\title{
Physical aging of polylactide-valsartan system investigated by differential scanning calorimetry
}

\author{
Agata Drogoń1), *), Marcin Skotnicki ${ }^{2)}$, Marek Pyda ${ }^{1), 3)}$ \\ DOI: dx.doi.org/10.14314/polimery.2020.7.5
}

\begin{abstract}
The polylactide-valsartan systems with a mass ratio of $20: 80,50: 50$ and $80: 20$ were obtained and characterized by standard Differential Scanning Calorimetry (DSC). The isothermal physical aging process of polylactide-valsartan with a mass ratio of 50:50 was investigated at the aging temperature of $50^{\circ} \mathrm{C}$ and $70^{\circ} \mathrm{C}$ for different aging times. The enthalpy of relaxation values for each of the aging times and for all investigated components were determined experimentally and fitted to the Kohlrausch-Williams-Watts equation.
\end{abstract}

Keywords: physical aging, enthalpy relaxation, polylactide, valsartan, Differential Scanning Calorimetry (DSC), Kohlrausch-Williams-Watts equation (KWW).

\section{Proces fizycznego starzenia układów polilaktyd-walsartan badany metodą różnicowej kalorymetrii skaningowej}

Streszczenie: Otrzymane układy polilaktydu z walsartanem w stosunkach masowych 20:80, 50:50 i $80: 20$ poddano analizie metodą różnicowej kalorymetrii skaningowej (DSC). Scharakteryzowano proces starzenia fizycznego mieszaniny polilaktyd-walsartan w stosunku masowym $50: 50$, prowadzony $\mathrm{w}$ temperaturze $50 \mathrm{i} 70^{\circ} \mathrm{C} \mathrm{w}$ różnym czasie. Z pomiarów doświadczalnych dla każdego czasu starzenia wyznaczono entalpię relaksacji, a następnie dopasowano otrzymane wielkości do równania Kohlrauscha-Williamsa-Wattsa.

Słowa kluczowe: starzenie fizyczne, entalpia relaksacji, polilaktyd, walsartan, różnicowa kalorymetria skaningowa (DSC), równanie Kohlrauscha-Williamsa-Wattsa (KWW).

Polylactide (PLA) is a biodegradable and biocompatible lactic acid polymer. It is composed of repeating mer units with a molar mass of $72.06 \mathrm{~g} / \mathrm{mol}$ [Formula (I)].

PLA contains a stereogenic centre thus it can appear in the L or D configuration. Depending on the content of<smiles>CC(C)(C)OC(=O)C(C)(C)C</smiles>

(I)

\footnotetext{
1) Rzeszów University of Technology, Department of Chemistry, al. Powstańców Warszawy 6, 35-959 Rzeszów, Poland.

2) Poznań University of Medical Sciences, Department of Pharmaceutical Technology, Grunwaldzka 6, 60-780 Poznań, Poland.

3) Poznań University of Medical Sciences, Department of Biophysics, Grunwaldzka 6, 60-780 Poznań, Poland.

*) Author for correspondence: agata.drogon@yahoo.pl
}

individual isomers in the chain, the polymers may differ in physicochemical properties [1-4]. The isomeric composition of PLA affects its degree of crystallinity as well as the biodegradation time. For example, studies $[5,6]$ have shown that the increase in the content of D-isomer in the chain results in, i.a., a reduction of glass transition temperature $\left(T_{g}\right)$, which has a significant impact on the physical aging process.

There are a vast array of applications for PLA, including medical, pharmaceutical and food industry. It can be used to make, among others, surgical sutures, orthopaedic and dental implants as well as foils and packaging $[7,8]$. In the pharmaceutical industry, it can be used in formulations in order to modify the dissolution profile of active pharmaceutical ingredient (API) or improve its stability [8-11]. For example, Agraval et al. achieved sustained release of drug - sulindac up to 20 days and tetracaine up to 10 days by applying triblock copolymer [polylactide-poly(ethylene oxide)-polylactide] while the release of these drugs without polymeric carriers occurs over $4-6 \mathrm{~h}$ [12].

The active pharmaceutical ingredients formulated into solid dosage forms (e.g. tablets or capsules) following oral administration must dissolve, usually in the gastric 
fluid and absorb in order to be pharmacologically active. However, about $40 \%$ of currently marketed pharmaceutical molecules and around $75 \%$ of new chemical entities exhibit significant aqueous solubility issue. Poor solubility and low dissolution rate often lead to poor bioavailability. This problem is highly relevant to poorly soluble class II (high permeability) substances according to the Biopharmaceutical Classification System (BCS). The limited bioavailability for those APIs may be enhanced by increasing the solubility and therefore the dissolution rate. An active pharmaceutical ingredient can exist in crystalline or amorphous form. The amorphous form of API is sometimes more desirable due to its usually greater apparent solubility and as a consequence bioavailability $[9,10]$. However, the amorphous form (high energy form) unlike crystalline, is usually unstable. Amorphous drugs may crystallize or, in the absence of a crystalline form, undergo physical aging process during storage at a temperature below the glass transition. Aged amorphous materials are characterized by increased fragility, and the aging process may result in a slower dissolution rate of the API [11-16]. Standalone amorphous APIs are rather not used in formulation development. In most cases, amorphous APIs are formulated with excipients in order to, amongst others, provide adequate absorption and to improve their stability [17-20].

Polymeric amorphous solid dispersion (PASD) is one of the widely investigated strategies to stabilize the amorphous drug. In PASD, the improved stability of amorphous API is achieved by entrapping the drug in a high energy glassy state between the polymer chains [21, 22]. Although the excipients are often considered inert, it is known that they can interact with APIs, changing their stability, absorption and bioavailability $[9,10]$. Therefore, throughout the drug development process API must be investigated during the pre-formulation studies to provide the necessary information to develop a stable formulation with adequate bioavailability [23-25]. If an amorphous drug-amorphous polymer system is completely miscible, only a single glass transition is observed with $T_{g}$ value between the $T_{q}$ 's of individual components. If the system is immiscible, two or more $T_{g}$ values may be detected [26]. The drug-polymer systems can also exhibit con-centration-dependent miscibility [27, 28]. For example, felodipine-poly(acrylic acid) systems containing 70\% or $90 \%$ polymer showed only one $T_{g}$, indicating miscible sys-tem, while systems containing $30 \%$ or $50 \%$ polymer showed two glass transitions, indicating the immiscibility in the blends [25].

Valsartan [VAL, Formula II)]) is a drug used in the management of hypertension and heart failure. Valsartan is marketed in a disordered form. Skotnicki et al. described two forms of disordered valsartan using differential scanning calorimetry solid-state nuclear magnetic resonance and powder X-ray diffractometry, i.e., fully amorphous material (AM) with glass transition around $76^{\circ} \mathrm{C}$ (fictive temperature), whereas the as-received, marketed form
(AR) with $T_{g}$ around $94^{\circ} \mathrm{C}$ overlapped with an enthalpy of relaxation peak [29-31]. However, it has to be noted that Guinet et al. described the marketed form (AR) using Raman spectroscopy, in terms of mesophase in which the long-range order of the stable crystal is limited on the length scale of tens nanometers [32]. The amorphous form of valsartan may undergo physical aging during storage of the formulation process and therefore, potentially changing its physicochemical and in consequence, therapeutic properties.<smiles>CCCCC(=O)N(Cc1ccc(-c2ccccc2-c2nn[nH]n2)cc1)[C@@H](C(=O)O)C(C)C</smiles>

(II)

The process of physical aging applies to amorphous materials and occurs below the glass transition temperature. During the aging process, the structure of the glassy material becomes more ordered. The amorphous glass, unlike the crystal, is not in a state of thermodynamic equilibrium. The physical aging is a reversible process. During the physical aging process, there is no break nor formation of new chemical bonds. The quantity that describes physical aging is the enthalpy of relaxation $\left(\Delta H_{\mathrm{r}}\right)$, which can be estimated by subtracting the difference between the total enthalpy of aged and non-aged material [33-40].

Enthalpy of relaxation $\left(\Delta H_{\mathrm{r}}\right)$ resulting from the physical aging process can be estimated directly from the heat flow $(\Phi)$ or specific heat $\left(C_{p}\right)$ measurements, from the difference of fields formed between heat flows or specific heats of aged and unaged sample and can be described by the Equation (1):

$\Delta H_{\mathrm{r}}=\frac{1}{q} \int_{T 1}^{T 2}\left(\Phi_{\text {aged }}-\Phi_{\text {unaged }}\right) \mathrm{d} T=\int_{T 1}^{T 2}\left(C p_{\text {aged }}-C p_{\text {unaged }}\right) \mathrm{d} T$

where $q$ - the heating rate, $T_{1}, T_{2}$ - limits of the integration temperature (where $T_{1}<T_{g}<T_{2}$ ), $\Phi_{\text {aged }} \Phi_{\text {unaged }}$ - heat flows originating from the aged and non-aged samples respectively, $C p_{\text {aged }}$ and $C p_{\text {unaged }}$ - heat capacities of the aged and non-aged samples, respectively, $\mathrm{d} T$ - the temperature change.

For the characterization of the physical aging process, an equilibrium enthalpy of relaxation $\left(\Delta H_{\mathrm{r}}^{\text {inf }}\right)$ is used, which determines the enthalpy of relaxation for infinite aging time $(t \rightarrow \infty)$ [33-41]. The equilibrium enthalpy of relaxation is determined by measuring the 
change in specific heat capacity in accordance with the Equation (2):

$$
\Delta H_{\mathrm{r}}^{\mathrm{inf}}=\int_{T \mathrm{a}}^{T g} \Delta C_{p} \mathrm{~d} T \approx \Delta C_{p}\left(T_{g}-T_{\mathrm{a}}\right)
$$

where; $\Delta C_{p}$ - the change of heat capacity in solid-liquid transition in a given temperature, $T_{g}$ and $T_{a}$ - the glass transition and aging temperature, respectively.

There are several empirical models in the literature describing the kinetics of the physical aging phenomenon. One of them is the Kohlrausch-Williams-Watts (KWW) model [42, 43] described by the Equation (3):

$$
\Delta H_{\mathrm{r}}=\Delta H_{\mathrm{r}}^{\mathrm{inf}}\left\{1-\exp \left[-\left(t / \tau^{\mathrm{KWW}}\right)^{\beta}\right]\right\}
$$

where: $\Delta H_{r}$ and - respectively the enthalpy of relaxation and equlibrium enthalpy relaxation, $t$ - the aging time, $\tau^{\mathrm{KWW}}$ - relaxation time, $\beta$ - the coefficient describing the distribution of relaxation times.

Showing the Equation (3) in a different form, recovery parameter $(\varphi)$ can be estimated as:

$$
\varphi=\exp \left(-t / \tau^{\mathrm{KWW}}\right)^{\beta}=1-\Delta H_{\mathrm{r}} / \Delta H_{\mathrm{r}}^{\mathrm{inf}}
$$

where all quantities in Equation (4) have the same meaning as in Equation (3).

Recovery parameter is an important quantity because it describes the kinetics of the physical aging process. From the recovery parameter correlation with aging time, it is possible to determine the departure from the equilibrium state. The recovery parameter not only shows relaxation enthalpy changes occurring during the physical aging process but also shows how much more the system can change under given conditions and how fast the material reaches equilibrium state. Recovery parameter has values from 1 for non-aged material to 0 for material whose relaxation enthalpy has reached the value of equilibrium enthalpy relaxation $[42,43]$.

As previously mentioned, PLA can be used as a API carrier. There is one study describing the combination of polylactide and valsartan and the aim of this study was to encapsulate valsartan within polyester microparticles, namely constituted of poly(lactic acid) (PLA) and poly( $\varepsilon$-caprolactone) (PCL), by using the emulsion solvent evaporation method [44].

In this study, fully amorphous polylactide (PLA-H) was used to form the system with valsartan. The aim of the study was to obtain polylactide-valsartan systems with different mass ratios to investigate miscibility and physical aging process of the system. Valsartan belongs to class II BCS (low solubility and high permeability) and is used in this study as a model amorphous drug to investigate the effect of the added polymer on physical aging process of VAL in the system with polylactide. The obtained PLA-H-valsartan systems with mass ratios of $20: 80,50: 50$ and $80: 20$ were subjected to the physical aging process at $50^{\circ} \mathrm{C}$ (both polymer and drug underwent aging process) and at $70^{\circ} \mathrm{C}$ (this is above $T_{g}$ of PLA-H, therefore, only valsartan underwent physical aging process). The relaxation enthalpies values obtained for the aged components of the system were fitted to the KWW equation, which allowed the determination of relaxation times and the distribution of relaxation times.

\section{EXPERIMENTAL PART}

\section{Materials}

The investigated materials in this study were the polylactide-valsartan (PLA-H-VAL) systems with three set mass ratios. The first component of these systems was a non-active pharmaceutical ingredient: a biodegradable and biocompatibile polymer, polylactide (PLA-H) [see Formula (I)] which has a chiral carbon atom in the repeating unit marked in the Formula (I) with the star. PLA-H contains $16.4 \%$ of the D-isomer in its chain, and it is a fully amorphous material [45], produced by Cargill Dow Nature-Works LLC. The second component of examined systems, an active pharmaceutical ingredient (API), was valsartan (VAL) [Formula(II)] and the sample was obtained from Polpharma, Starogard Gdański, Poland.

\section{Samples preparations}

The PLA-H-VAL systems with following mass ratios of $20: 80,50: 50$ and $80: 20$ were prepared by a solvent evaporation method. For each mixture, $10-20 \mathrm{mg}$ of VAL and PLA-H were used in adequate proportions and were dissolved in $50 \mathrm{~cm}^{3}$ of chloroform followed by evaporation of the solvent under reduced pressure at about $55-60^{\circ} \mathrm{C}$ in a rotary evaporator. Next, polymer-API systems were dried at $40^{\circ} \mathrm{C}$ for 2 days. The obtained materials were in the form of a brittle, thin film. Standalone PLA-H and standalone VAL were also dissolved in chloroform and treated in the same way as PLA-H-VAL systems.

\section{Methods of testing}

Differential Scanning Calorimetry (DSC) curves were obtained using a differential scanning calorimeters: DSC Q2500, DSC Q1000 and DSC 2920 from TA Instrument USA. The temperature and heat-flow rate measured by the DSC equipments were calibrated with indium (m.p. $=156.65^{\circ} \mathrm{C}, \Delta H_{\mathrm{f}}=28.45 \mathrm{~J} / \mathrm{g}$ ) [33], and at least two tests were run on each sample. Sapphire $\left(\mathrm{Al}_{2} \mathrm{O}_{3}\right)$ was used to calibrate heat capacity [33].

Thin film samples of the examinated PLA-VAL systems (1-10 mg) were placed in a standard aluminum pan. For standard thermal analysis, the samples were heated from $5^{\circ} \mathrm{C}$ to $140^{\circ} \mathrm{C}$ with the constant heating rate of $10^{\circ} \mathrm{C} / \mathrm{min}$. Next, the samples were cooled to $5^{\circ} \mathrm{C}$ and then reheated to $140^{\circ} \mathrm{C}$ in a second run. For thermal analysis of the isothermal physical aging process, the measurements were carried out at aging temperatures $T_{a}=50^{\circ} \mathrm{C}$ (physical 
aging of PLA-H and VAL) and $70^{\circ} \mathrm{C}$ (physical aging of VAL). Before annealing, samples were heated to $140^{\circ} \mathrm{C}$ to erase previous thermal history, then cooled down to chosen aging temperature and annealed for different aging times. After every tested aging time, the samples were rapidly cooled down to $5^{\circ} \mathrm{C}$ and then heated at a constant heating rate of $10^{\circ} \mathrm{C} / \mathrm{min}$ again to $140^{\circ} \mathrm{C}$. During this heating, the data for aged sample were collected.

\section{RESULTS AND DISCUSSION}

Figure 1 presents the results obtained from the standard DSC measurement as a plot of heat-flow changes with temperature for standalone valsartan (VAL), standalone polylactide (PLA-H), and for the (PLA-H-VAL) systems with different mass ratios $(20: 80,50: 50$ and $80: 20$, respectively).

On the heat-flow as a function of temperature trace for standalone valsartan, one glass transition is observed at $71.3 \pm 0.5^{\circ} \mathrm{C}$ which is in good agreement with literature [29-31]. PLA-H is also characterized by one glass transition around $56.5 \pm 0.3^{\circ} \mathrm{C}$, which is also in good agreement

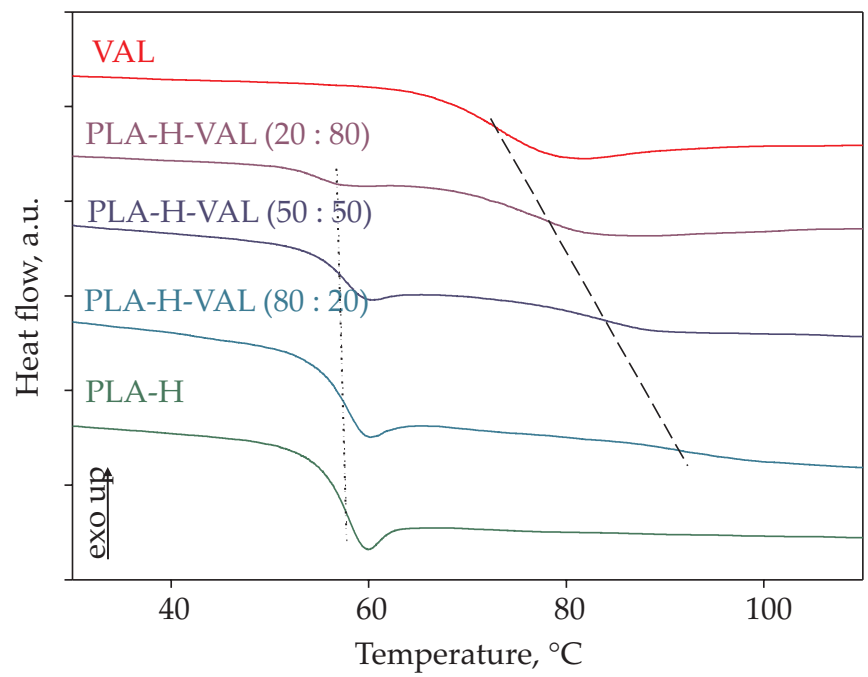

Fig. 1. Heat-flow rate dependence on temperature for: valsartan (VAL), polylactide (PLA-H) and polylactide-valsartan (PLA-H-VAL) systems with different mass ratios (20:80, 50:50 and $80: 20)$ obtained from standard DSC measurements with constant heating rate of $10^{\circ} \mathrm{C} / \mathrm{min}$ with the literature [4]. In addition, a small endothermic peak of enthalpy relaxation at the glass transition region for standalone PLA-H is observed, resulting from the aging process occurring during standard DSC measurement. The examinated PLA-H-VAL systems are characterized by two glass transitions - the first one derived from the PLA-H, and the second from VAL. Coexistence of these two glass transitions indicates that the system is immiscible. As a result of the glass transition analysis, the glass transition temperature, $T_{g^{\prime}}$ and the changes of the heat capacity, $\Delta C_{p^{\prime}}$ at $T_{g}$ were determined for PLA- $H$ and VAL for the components of the tested systems as well as for the standalone, individual substances. The results of the glass transition analysis are presented in Table 1.

The addition of PLA-H to valsartan causes an increase in the glass transition temperature $T_{g}$ of the drug from $71.3 \pm 0.5^{\circ} \mathrm{C}$ for standalone valsartan to $91.9 \pm 1.7^{\circ} \mathrm{C}$ in the PLA-H-VAL system with mass ratio $80: 20$. Changes of the heat capacity $\left(\Delta C_{p}\right)$ at the glass transition temperature $\left(T_{q}\right)$ of polylactide and valsartan as components of the tested systems are proportional to the mass content of the individual components.

Increase in the glass transition temperature may potentially be a sign of increased stability [17-22]. In this case, valsartan may be incorporated as molecular dispersion in a glassy polylactide matrix, stabilized by physical separation of the molecules inside the polymer chains [46]. PLA-H in this system acts as a stabilizer by decreasing molecular mobility of VAL. The reason for this can be the strong solid-state interactions between the components [47]. In majority of the studies, the physical stability of co-amorphous systems is assigned to intermolecular interactions such as hydrogen bonds, $\pi-\pi$, or ionic interactions [48]. Although, the co-amorphous dispersions can increase the stability of the components even in the absence of interactions due to molecular mixing [49]. In the study [50] an inactive pharmaceutical ingredient polyvinylpyrrolidone K25 (PVP K25) was found to be effective in stabilization of ketoconazole (prevented crystallization). The absence of strong and specific drug-polymer interactions were confirmed with ${ }^{13} \mathrm{C}$ Nuclear Magnetic Resonance $\left({ }^{13} \mathrm{C}\right.$ NMR) and Fourier Transform Infrared Spectroscopy (FT-IR). Therefore, it was concluded that the physical mechanism of the protective effect of PVP K25

T a b l e 1. Glass transition temperatures $T_{g}$ and changes of the heat capacity, $\Delta C_{p}$, at $T_{g}$ for standalone polylactide (PLA-H), standalone valsartan (VAL), and for the PLA-H and VAL as a components of examinated polymer-drug systems

\begin{tabular}{c|c|c|c|c}
\hline Sample & $\begin{array}{c}\text { Glass transition } \\
\text { temperature } \\
T_{g 1}(\mathrm{PLA}-\mathrm{H}),{ }^{\circ} \mathrm{C}\end{array}$ & $\begin{array}{c}\text { Change of heat capacity } \\
\text { at } T_{\mathrm{g}}\end{array}$ & $\begin{array}{c}\text { Glass transition } \\
\text { temperature }\end{array}$ & $\begin{array}{c}\text { Change of heat capacity } \\
\text { at } T_{\mathrm{g}}\end{array}$ \\
\hline PLA-H & $56.5 \pm 0.3$ & $0.517 \pm 0.08$ & $T_{\mathrm{g} 2}(\mathrm{VAL}),{ }^{\circ} \mathrm{C}$ & $\Delta C_{p 2}(\mathrm{VAL}), \mathrm{J} / \mathrm{g} / \mathrm{K}$ \\
\hline Valsartan (VAL) & - & - & - & - \\
PLA-H-VAL 20 : 80 & $56.6 \pm 0.4$ & $0.131 \pm 0.01$ & $78.0 \pm 0.5$ & $0.379 \pm 0.08$ \\
PLA-H-VAL 50:50 & $57.3 \pm 0.3$ & $0.251 \pm 0.02$ & $80.9 \pm 1.5$ & $0.266 \pm 0.01$ \\
PLA-H-VAL 80 : 20 & $56.1 \pm 0.4$ & $0.401 \pm 0.05$ & $91.9 \pm 1.7$ & $0.128 \pm 0.04$ \\
\hline
\end{tabular}


in the case of amorphous ketoconazole is not the consequence of the interactions between the polymer and the drug, but it mainly results from the polymer anti-plasticizing effect [50]. In one study [51], the FT-IR spectra were presented for standalone valsartan, PLA, polycaprolactone (PCL) and valsartan-loaded microparticles. It was noted that the PLA and PCL bands appeared in the spectra of the microparticles without any changes in their wave number, indicating no interactions between polymers and valsartan.

According to study [52], amorphous solid dispersions (ASD) can be thermodynamically stable if the drug loading of the ASD is below the solid solubility of the drug in the polymer. It was confirmed that the more physically stable the amorphous drug alone, the more physically stable the corresponding ASDs $[53,54]$.

The polylactide-valsartan system with mass ratio $50: 50$ was subjected to the isothermal physical aging process. As it was mentioned earlier, this process only applies to amorphous materials and occurs at temperatures below $T_{g}$. Therefore, at aging temperature $T_{a}=50^{\circ} \mathrm{C}$, both components of the system undergo physical aging process, while at $T_{a}=70^{\circ} \mathrm{C}$ only valsartan from the system undergoes aging process, because this is temperature above the glass transition of PLA-H and the polymer exists in such conditions as an amorphous liquid. Figure 2 shows the heat flow changes as a function of the temperature for PLA-H-VAL (50 : 50) system subjected to the isothermal physical aging process at aging temperature $T_{a}=50^{\circ} \mathrm{C}$. The results were obtained for aging times from 5 min up to 28 days.

It can be seen in Fig. 2 that as the aging time increases, also the area of the endothermic relaxation peaks increase and the maxima of these peaks shift towards higher temperature values.

Figure 3 presents the dependence of the relaxation enthalpy for tested PLA-H-VAL system with 50 : 50 mass ratio versus aging time for the physical aging process

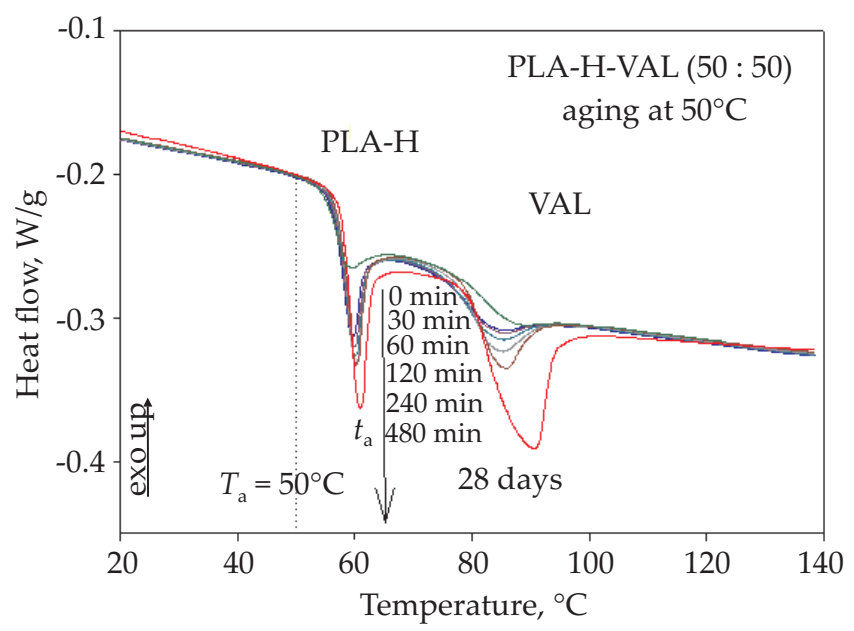

Fig. 2. Heat-flow as a function of temperature for the PLA-H-VAL system with a mass ratio of $50: 50$, obtained as a result of aging at $50^{\circ} \mathrm{C}$ for aging times up to 28 days

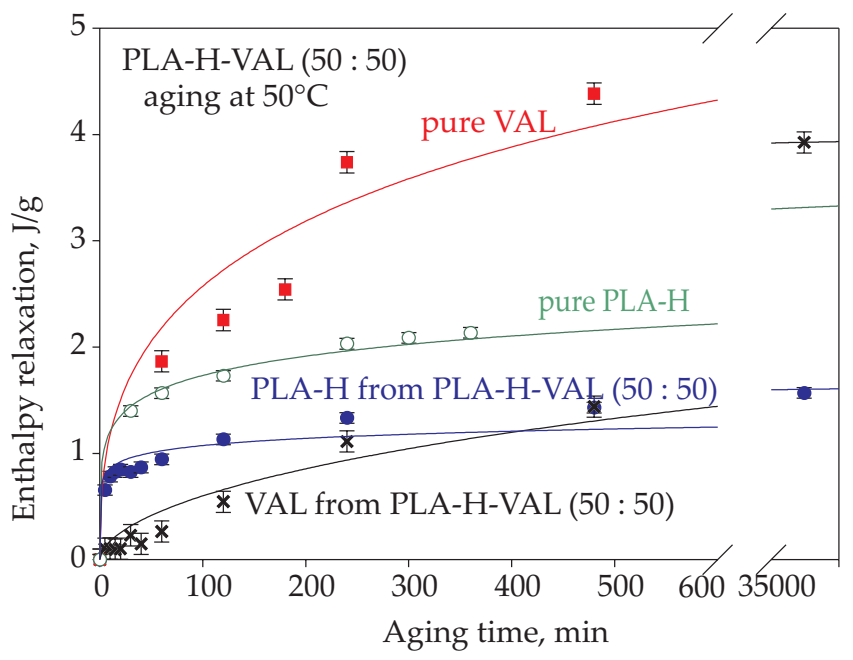

Fig. 3. Experimental enthalpy relaxation as a function of aging time for PLA-H (blue dots) and VAL (black crosses) from the PLA-H-VAL (50:50) system aged isothermally at $T_{\mathrm{a}}=50^{\circ} \mathrm{C}$ and their fit to the KWW equation; red squares are for standalone VAL aged at $50^{\circ} \mathrm{C}$, green dots represent the values obtained from the same aging temperature for standalone PLA-H and they were taken from the literature [55]

carried out at the aging temperature $T_{a}=50^{\circ} \mathrm{C}$. Enthalpy of relaxation was determined as the difference of fields created between the heat flow courses for non-aged and aged sample, according to the method described in the literature [34-39], Equation (1).

Figure 3 shows experimental values of the enthalpy relaxation marked by red squares for standalone valsartan and the green circles for standalone PLA-H, both aged at $50^{\circ} \mathrm{C}$. Points in Fig. 3 represent the mean values from several calculations and the error bars are standard deviation from the obtained values of enthalpy relaxation $( \pm 0.1 \mathrm{~J} / \mathrm{g}$ for VAL and $\pm 0.05 \mathrm{~J} / \mathrm{g}$ for PLA-H). Results for standalone PLA-H has been obtained from the literature [55]. Solid lines in Fig. 3 represents the adjustments of the KWW equation for the obtained experimental data. It can be seen that the relaxation enthalpy values for VAL from the mixture after multiplying by 2 (since the weight proportion of valsartan in the mixture is 50\%) are still lower than the results obtained from the same physical aging experiment conducted for standalone valsartan. It can, therefore, be assumed that the addition of the PLA-H to valsartan results in improved physical stability of the drug.

Figure 4 shows changes in the heat-flow rate as a function of temperature for unaged and aged PLA-H-VAL $(50: 50)$ system annealed at $70^{\circ} \mathrm{C}$ for aging times up to $600 \mathrm{~min}$. According to the initial hypothesis, only valsartan coming from the examined system undergoes physical aging in the specified conditions, because at $70^{\circ} \mathrm{C}$ polylactide occurs in the amorphous phase of the liquid state. Analysis of the experimental results in this case, reveals an increase in the endothermic enthalpy relaxation peaks emerging in the glass transition region of VAL in the tested system and their shift towards higher 
a)

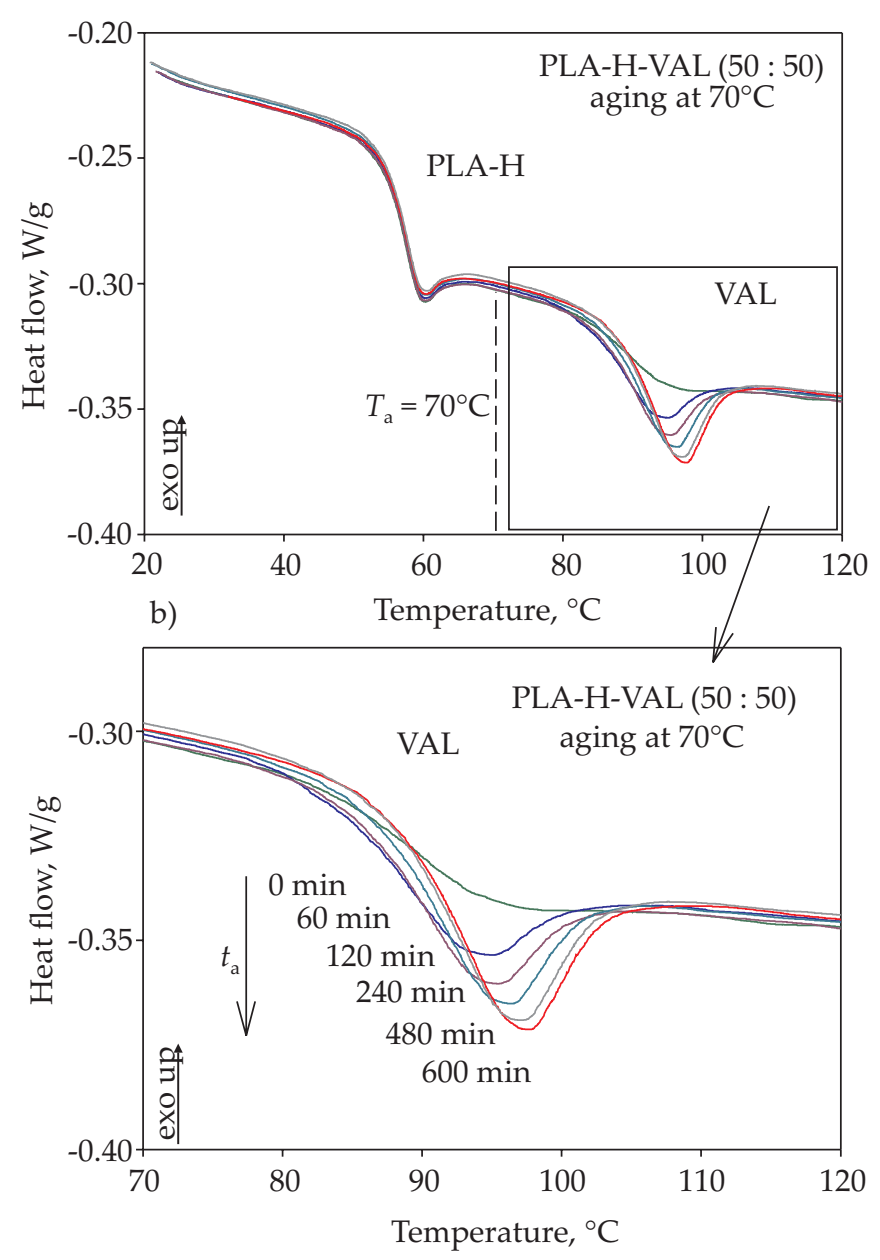

Fig. 4. Heat-flow rate as a function of temperature: a) for the PLA-H-VAL system with a mass ratio of $50: 50$, obtained as a result of an isothermal physical aging process carried out at $70^{\circ} \mathrm{C}$ for aging times up to $600 \mathrm{~min}, \mathrm{~b}$ ) the enlargement of the heatflow rate of the physical aging of valsartan (VAL) for the different aging times

temperatures as the aging time of the sample increases. It can also be observed, that although the PLA-H does not undergo aging process at $70^{\circ} \mathrm{C}$, the heat-flow rate in the glass temperature region of PLA-H in the system is

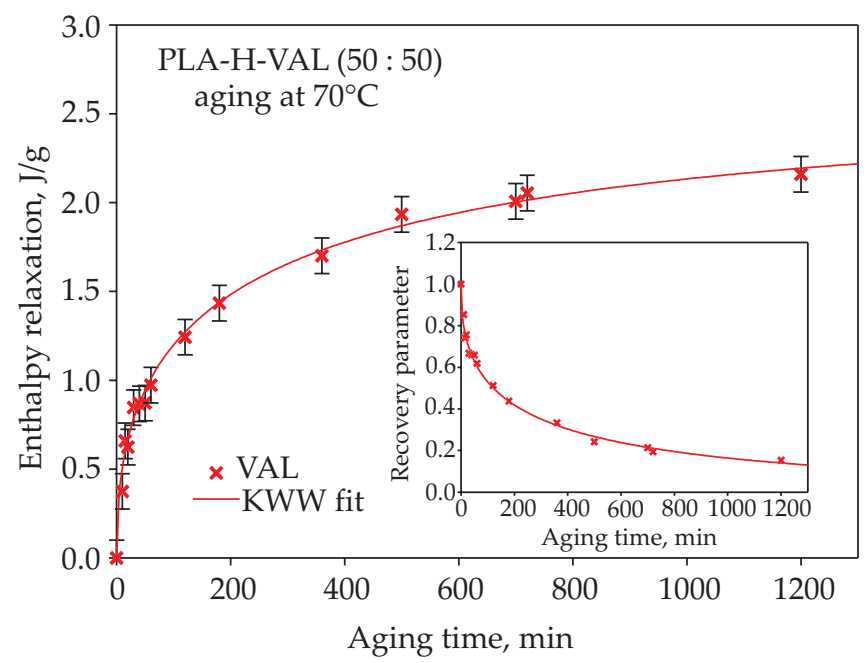

Fig. 5. Experimental enthalpy relaxation as a function of aging time for valsartan in the PLA-H-VAL (50:50) system aged at $70^{\circ} \mathrm{C}$ and fit of the KWW equation to the calculated values of $\Delta H_{\mathrm{r}^{\prime}}$ the inner plot presents the recovery parameter as a function of aging time

fraught with small endothermic changes due to non-isothermal aging process occurring during measurements.

In Fig. 5, the graphical representation of the enthalpy relaxation changes as the function of aging time for VAL from the PLA-H-VAL $(50: 50)$ system aged at $T_{\mathrm{a}}=70^{\circ} \mathrm{C}$ was showed. The solid line in Fig. 5 is the fit of the KWW equation to the experimental data. The standard deviation is $\pm 0.1 \mathrm{~J} / \mathrm{g}$. The inner plot in Fig. 5 is the recovery parameter as the function of aging time. It can be seen that after 20 hours of annealing the PLA-H-VAL (50:50) system at $70^{\circ} \mathrm{C}$, VAL from the system reaches $80 \%$ relaxation - the value of recovery parameter decreases to 0.2 . Calculated parameters of the KWW equation for studied materials and aging temperatures are summarized in Table 2.

Figure 6 presents the comparison of the changes in the recovery parameter for PLA-H and VAL from the PLA-H-VAL $(50: 50)$ system aged at $50^{\circ} \mathrm{C}$. The same experiment was also carried out for standalone VAL and the results for aged standalone PLA-H are taken from

T a b 1 e 2. Fitting parameters of experimental data to Kohlrausch-Williams-Watts equation (KWW) for PLA-H and VAL from PLA-H-VAL (50:50) mixture during the isothermal physical aging process at $T_{\mathrm{a}}=50^{\circ} \mathrm{C}$ and $70^{\circ} \mathrm{C}$ temperature

\begin{tabular}{|c|c|c|c|c|c|c|}
\hline & \multicolumn{3}{|c|}{$T_{\mathrm{a}}=50^{\circ} \mathrm{C}$} & \multicolumn{3}{|c|}{$T_{a}=70^{\circ} \mathrm{C}$} \\
\hline & $\begin{array}{c}\Delta H_{\mathrm{r}}^{\mathrm{inf}} \\
\mathrm{J} / \mathrm{g}\end{array}$ & $\beta$ & $\stackrel{\tau}{\min (h)}$ & $\begin{array}{c}\Delta H_{\mathrm{r}}^{\mathrm{inf}} \\
\mathrm{J} / \mathrm{g}\end{array}$ & $\beta$ & $\underset{\min (h)}{\tau}$ \\
\hline $\begin{array}{c}\text { PLA-H } \\
\text { (from the PLA-H-VAL }(50: 50) \text { system) }\end{array}$ & 1.8 & 0.145 & $\begin{array}{l}237.7 \\
(3.96)\end{array}$ & - & - & - \\
\hline $\begin{array}{c}\text { VAL } \\
\text { (from the PLA-H-VAL }(50: 50) \text { system) }\end{array}$ & 4.0 & 0.567 & $\begin{array}{c}2429.87 \\
(40.5)\end{array}$ & 2.5 & 0.4548 & $271(4.5)$ \\
\hline Standalone PLA-H & 3.8 & 0.202 & $\begin{array}{l}1252.8 \\
(20.88)\end{array}$ & - & - & - \\
\hline Standalone VAL & 8.1 & 0.387 & $\begin{array}{c}1192.34 \\
(19.87)\end{array}$ & - & - & - \\
\hline
\end{tabular}




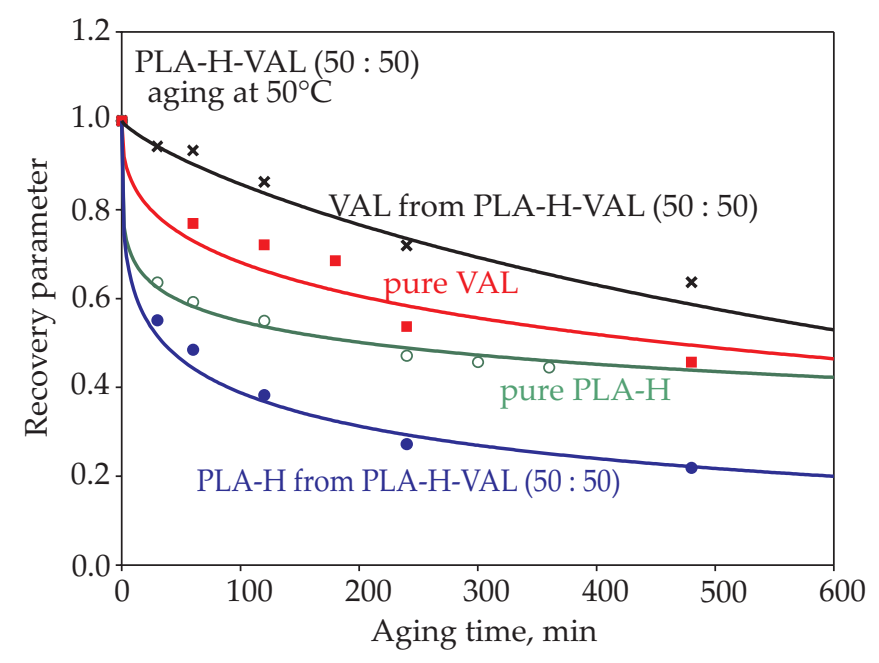

Fig. 6. Comparison of the recovery parameter for examinated PLA-H-VAL system, standalone PLA-H and standalone VAL after isothermal annealing at $T_{\mathrm{a}}=50^{\circ} \mathrm{C}$

the literature [54]. It can be seen that valsartan in the system with PLA-H is aging much more slowly compared to the standalone drug. The relaxation time determined by fitting the KWW equation to the obtained results for VAL in the mixture is more than twice as high as it is for standalone valsartan. The addition of PLA-H to VAL may increase the physical stability of the API in the formulation. Conversely, in the case of PLA-H, the presence of VAL in the mixture causes a 5-fold decrease in the relaxation time for PLA- $\mathrm{H}$ from the system aged at $50^{\circ} \mathrm{C}$ compared to standalone PLA-H. PLA-H from the PLA-H-VAL (50:50) system after storage for $200 \mathrm{~min}$ at $50^{\circ} \mathrm{C}$ reaches out $80 \%$ of the equilibrium enthalpy relaxation value for PLA-H in the system and after 28 more days at $50^{\circ} \mathrm{C}$, both the enthalpy relaxation and the recovery parameter remains unchanged while the enthalpy of the relaxation for VAL in such system increases more than 3-times.

\section{CONCLUSIONS}

Using differential scanning calorimetry, the glass transition regions of obtained PLA-H-VAL systems with three specified mass ratios $(80: 20,50: 50$ and $20: 80)$ were analyzed. The presented study demonstrated that PLA-H-VAL system is immiscible, how-ever the presence of PLA-H results with an increase in the glass transition temperature of VAL in such system and hence has a significant impact on the kinetics of the physical aging process of the drug. The physical aging process of the PLA-H-VAL system with a $50: 50$ mass ratio was studied at the aging temperature $T_{\mathrm{a}}=50$ and $70^{\circ} \mathrm{C}$. It has been shown that both components of the tested system undergo the physical aging process at $50^{\circ} \mathrm{C}$, while at $70^{\circ} \mathrm{C}$ only valsartan from the system ages. Moreover, physical aging process at $50^{\circ} \mathrm{C}$ was also conducted for standalone valsartan and standalone PLA-H for comparison. The KWW equation was fitted to all of the results and the relaxation time and $\beta$ parameter describing the dis- tribution of relaxation times physical aging process were estimated. Calculated relaxation time for aging at $50^{\circ} \mathrm{C}$ for VAL in the 50:50 (w/w) system with PLA-H is twice as high as the relaxation time for standalone VAL which may result in increased stability of the drug. On the other hand, PLA-H in a mixture with VAL, compared to standalone polymer, reaches saturation relatively quickly and after 6 hours at $50^{\circ} \mathrm{C}$, further changes in the enthalpy of relaxation due to physical aging are not noticeable.

\section{ACKNOWLEDGMENTS}

MS gratefully acknowledge Mr Artur Strzelecki from TA Instruments Waters Sp. z o.o. (Warsaw, Poland) for the provision of Discovery DSC 2500 instrument used in this study. Also, the authors acknowledge Polpharma SA Company (Starogard Gdanski, Poland) for supplying the valsartan used in this study. AD sincerely thanks prof. Janina Lulek, Head of the Pharmaceutical Technology Department (Poznan University of Medical Sciences) for the opportunity to undergo the internship during which the presented research was carried out.

\section{REFERENCES}

[1] Pyda M., Bopp R.C., Wunderlich B.: The Journal of Chemical Thermodynamics 2004, 36, 731.

https://doi.org/10.1016/j.jct.2004.05.003

[2] Magoń A., Pyda M.: Polymer 2009, 50, 3967. https://doi.org/10.1016/j.polymer.2009.06.052

[3] Pyda M.: Encyclopedia of Polymer Science and Technology 2014, 1-30. https://doi.org/10.1002/0471440264.pst623

[4] Cai H., Dave V., Gross R.A., McCarthy S.P.: Journal of Polymer Science: Part B: Polymer Physics 1996, 34, 2701. h t t p s: / / d o i or g / 10.1002 / ( S I C I ) 1099 0488(19961130)34:16<2701::AID-POLB2>3.0.CO;2-S

[5] Kwon M., Lee S.C., Jeong Y.G.: Macromolecular Research 2010, 18 (4), 346. https://doi.org/10.1007/s13233-010-0410-7

[6] Aou K., Hsu S.L., Kleiner L.W. et al.: Journal of Physical Chemistry B 2007, 111 (42), 12322. http://dx.doi.org/10.1021/jp074509t

[7] "Poly(lactic acid) synthesis, structures, properties, processing, and application" (Eds. Auras R., Lim L.T., Selke S.E.M., Tsuji H., John Wiley \& Sons, 2010. http://dx.doi.org/10.1002/9780470649848

[8] Garlotta D.: Journal of Polymers and the Environment 2001, 9, 63.

https://doi.org/10.1023/A:1020200822435

[9] Hancock B.C., Parks M.: Pharmaceutical Research 2000, 17 (4), 397.

http://dx.doi.org/10.1023/a:1007516718048

[10] Hancock B.C., Zografi G.: Journal of Pharmaceutical Sciences 1997, 86 (1), 1. http://dx.doi.org/10.1021/js9601896

[11] Guo J.H., Robertson R.E., Amidon G.L.: Pharmaceutical Research 1991, 8, 1500. http://dx.doi.org/10.1023/a:1015890232106 
[12] Agraval S.K., Sanabria-DeLong N., Coburn J.M. et al.: Journal of Controlled Release 2006, 112, 64. https://doi.org/10.1016/j.jconrel.2005.12.024

[13] Kucera S.A., Felton L.A., McGinity J.W.: International Journal of Pharmaceutics 2013, 457, 428. http://dx.doi.org/10.1016/j.ijpharm.2013.01.069

[14] Surana R., Pyne A., Suryanarayanan R.: Pharmaceutical Research 2004, 21, 867. https://doi.org/10.1023/B:PHAM.0000026441.77567.75

[15] Pokharkar V.B., Mandpe L.P., Padamwar M.N. et al.: Powder Technology 2006, 167, 20. https://doi.org/10.1016/j.powtec.2006.05.012

[16] Graeser K.A., Patterson J.E., Zeitler J.A. et al.: European Journal of Pharmaceutical Sciences 2009, 37, 492. https://doi.org/10.1016/j.ejps.2009.04.005

[17] Julio T.A., Zamara I.F., Garcia J.S., Trevisan M.G.: Brazilian Journal of Pharmaceutical Sciences 2013, 49 (4). http://dx.doi.org/10.1590/S1984-82502013000400003

[18] Liechty W.B., Kryscio D.R., Slaughter B.V., Peppas N.A.: Annual Review of Chemical and Biomolecular Engineering 2010, 1, 149.

http://dx.doi.org/10.1146/annurev-chembioeng-073009-100847

[19] Dengale S.J., Grohganz H., Rades T., Löbmann K.: Advanced Drug Delivery Reviews 2016, 100, 116. http://dx.doi.org/10.1016/j.addr.2015.12.009

[20] Chavan R.B., Thipparaboina R., Kumar D., Shastri N.R.: International Journal of Pharmaceutics 2016, 515, 403. http://dx.doi.org/10.1016/j.ijpharm.2016.10.043

[21] Bikiaris D.N.: Expert Opinion on Drug Delivery 2011, 8 (11), 1501. https://doi.org/10.1517/17425247.2011.618181

[22] Qian F., Huang J., Hussain M.A.: Journal of Pharmaceutical Science 2010, 99 (7), 2941. https://doi.org/10.1002/jps.22074

[23] Blasko A., Leahy-Dios A., Nelson W. et al.: Monatshefte fur Chemie 2001, 132, 789. https://doi.org/10.1007/s007060170065

[24] Tiwari R., Tiwari G., Srivastava B., Raiet A.K.: International Journal of PharmTech Research 2009, 1 (4), 1338.

[25] Sihna S., Ali M., Baboota S. et al.: AAPS PharmSciTech 2010, 11 (2), 518. http://dx.doi.org/10.1208/s12249-010-9404-1

[26] Rumondor A., Ivanisevic I., Bates S. et al.: Pharmaceutical Research 2009, 26, 2523. http://dx.doi.org/10.1007/s11095-009-9970-7

[27] Newman A., Munson E.: American Pharmaceutical Review 2012, 3, 92.

[28] Al-Obaidi H., Lawrence M.J., Shah S. et al.: International Journal of Pharmaceutics 2013, 446, 100. https://doi.org/10.1016/j.ijpharm.2013.02.009

[29] Skotnicki M., Gaweł A., Cebe P., Pyda M.: Drug Development and Industrial Pharmacy 2013, 39, 1508. https://doi.org/10.3109/03639045.2012.704379

[30] Skotnicki M., Apperley D.C., Aguilar J.A. et al.: Molecular Pharmaceutics 2016, 13 (1), 211. http://dx.doi.org/10.1021/acs.molpharmaceut.5b00646

[31] Skotnicki M., Aguilar J.A., Pyda M., Hodgkinson P.: Pharmaceutical Research 2015, 32, 414.

http://dx.doi.org/10.1007/s11095-014-1471-7

[32] Guinet Y., Paccou L., Danède F. et al.: International Journal of Pharmaceutics 2017, 526 (1-2), 209. http://dx.doi.org/10.1016/j.ijpharm.2017.04.067

[33] Wunderlich B.: "Thermal Analysis of Polymeric Materials", Spring, Verlag, Berlin 2005. https://doi.org/10.1007/b137476

[34] Struik L.C.E.: "Physical aging in amorphous polymers and other materials", Elsevier Science, 1980. https://doi.org/10.1016/0079-6700(94)00001-I

[35] Cernošek Z., Holubová J., Cernošková E., Liška M.: Journal of Optoelectronics and Advanced Materials 2002, $4,489$.

[36] Hutchinson J.M.: Progress in Polymer Science 1995, 20, 703. https://doi.org/10.1016/0079-6700(94)00001-I

[37] Hodge I.M.: Journal of Non-Crystalline Solids 1994, 169, 211. https://doi.org/10.1016/0022-3093(94)90321-2

[38] Hay J.N.: Pure and Applied Chemistry 1995, 67, 1855. https://doi.org/10.1002/masy.19991430112

[39] Koh Y.P., Simon S.L.: Macromolecules 2013, 46, 5815. https://doi.org/10.1021/ma4011236

[40] Morris C., Taylor A.J. et al.: Carbohydrate Research 2011, 346, 1122. https://doi.org/10.1016/j.carres.2011.04.009

[41] Moynihan C.T., Macedo P.B., Montrose C.J. et al.: Annals of the New York Academy of Sciences 1976, 279, 15. https://doi.org/10.1111/j.1749-6632.1976.tb39688.x

[42] Kohlrausch R.: Annals of Physics 1847, 12, 393.

[43] Williams G., Watts D.C.: Transactions of the Faraday Society 1970, 66, 80. https://doi.org/10.1039/tf9706600080

[44] Sadoun O., Rezgui F., G'Sell C.: Materials Science \& Engineering C 2018, 90, 189. http://dx.doi.org/10.1016/j.msec.2018.04.041

[45] Malmgren T., Mays J., Pyda M.: Journal of Thermal Analysis and Calorimetry 2006, 83, 35. https://doi.org/10.1007/s10973-005-7066-0

[46] Karagianni A., Kachrimanis K., Nikolakakis I.: Pharmaceutics 2018, 10 (3), 98. http://dx.doi.org/10.3390/pharmaceutics10030098

[47] Laitinen R., Löbmann K., Strachan C.J. et al.: International Journal of Pharmaceutics 2013, 453, 65. http://dx.doi.org/10.1016/j.ijpharm.2012.04.066

[48] Zhu S., Gao H., Babu S., Garad S.: Molecular Pharmaceutics 2018, 15, 97. http://dx.doi.org/10.1021/acs.molpharmaceut.7b00738

[49] Löbmann K., Strachan C., Grohganz H. et al.: European Journal of Pharmaceutics and Biopharmaceutics 2012, 81, 159. http://dx.doi.org/10.1016/j.ejpb.2012.02.004

[50] Van den Mooter G.: European Journal of Pharmaceutical Sciences 2001, 12, 261. http://dx.doi.org/10.1016/s0928-0987(00)00173-1 
[51] Sadoun O., Rezgui F., G'Sell C.: Materials Science \& Engineering C 2018, 90, 189. https://doi.org/10.1016/j.msec.2018.04.041

[52] Qian F., Huang J., Hussain M.: Journal of Pharmaceutical Sciences 2010, 99 (7), 2941. http://dx.doi.org/10.1002/jps.22074

[53] Ng Y.C., Yang Z.Y., McAuley W.J., Qi S.: European Journal of Pharmaceutics and Biopharmaceutics 2013, 84 (3), 555. http://dx.doi.org/10.1016/j.ejpb.2013.01.008

[54] Yang Z., Nollenberger K., Albers J.et al.: Pharmaceutical Research 2015, 32 (4), 1210.

http://dx.doi.org/10.1007/s11095-014-1527-8

[55] Drogoń A., Pyda M.: Polimery 2019, 64, 127. http://dx.doi.org/10.14314/polimery.2019.2.6

Received 22 I 2020. 